\title{
Anomalous Dynamics of Tropospheric Ozone in the Spring of 2020 in Central Russia
}

\author{
S. N. Kotelnikov ${ }^{a, *}$ and E. V. Stepanov ${ }^{a, * *}$ \\ ${ }^{a}$ Prokhorov General Physics Institute, Russian Academy of Sciences, Moscow, 119991 Russia \\ *e-mail: skotelnikiov@mail.ru \\ **e-mail: EugeneStepanov@yandex.ru
}

Received September 5, 2020; revised September 15, 2020; accepted September 16, 2020

\begin{abstract}
Anomalously low ozone concentrations in the surface atmosphere in central Russia were recorded in spring of 2020. The increase in the ozone content usual for spring due to a seasonal increase in the temperature and light was followed by a monotonic decrease. The maximum daily values of surface ozone concentrations averaged over the month in April 2020 were three times less than the values recorded at the same time in 2019. Both a decrease in regional background ozone concentrations in the near-surface atmosphere and a decrease in the intensity of its photochemical formation were observed. The most probable cause of the observed phenomenon is a decrease in combustion product emissions into the atmosphere in China, Europe, and Russia due to the introduction of special regimes in connection with the COVID-19 pandemic.
\end{abstract}

Keywords: tropospheric ozone, atmospheric pollution, photochemical ozone formation, COVID-19 pandemic

DOI: $10.3103 / \mathrm{S} 1068335621030076$

\section{INTRODUCTION}

Continuous and long-term monitoring of the ozone concentration $\left(\mathrm{O}_{3}\right)$ in the near-surface atmosphere is performed in the pure (background) region of the central Russia over the past 12 years [1].

The monitoring station is arranged at the point with coordinates $56^{\circ} 13^{\prime} \mathrm{N}, 51^{\circ} 4^{\prime} \mathrm{E}$ at the Vyatskie Polyany, Kirov oblast. This place is removed from the nearest large cities for more than $100 \mathrm{~km}$; there are no industrial enterprises.

The station is equipped with instrumentation for automated monitoring of ozone concentration and meteoparameters. The devices are used, certificated for applications in high-accuracy monitoring and subjected to regular certification and calibration. To measure the $\mathrm{O}_{3}$ content, a 3.02P-A chemiluminescent analyzer (OPTEK Company, Russia) is used. Analyzed atmospheric air was continuously pumped through a device measuring cell. The analyzer sensitivity was $1 \mu \mathrm{g} / \mathrm{m}^{3}$, the measurement periodicity was $1 \min [2]$.

Ozone is formed in the surface atmosphere due to a cycle of photochemical reactions in the presence of precursor compounds, i.e., nitrogen oxides, carbon monoxide, and volatile hydrocarbons. The presence of ozone in the surface atmosphere indicates atmospheric air contamination by combustion products ejected by car and air transport, thermal power plants and other industrial sources, as well as by forest fires. Ozone in the surface atmosphere is an integral indicator of the ambient air quality. The tropospheric ozone formation rate increases with temperature and light and is maximum in the spring-summer period.

Main features of seasonal and diurnal ozone variations caused by environmental temperature and humidity variability, solar illumination intensity and duration are studied in sufficient detail.

Furthermore, the ozone content balance in the surface atmosphere is controlled by many other factors, among which are the air pollution, horizontal transfer and vertical transfer from upper layers, scavenging and dry deposition during the interaction with the ground surface, and others.

The typical annual variation of the ozone concentration in the surface atmosphere is shown in Fig. 1. Rapid and significant variations in the ozone concentration in the atmosphere, shaped as random noise in this figure, are caused by regular diurnal variations. There are easily seen a gradual increase in the ozone concentration in air in spring and high maximum levels in the summer months, reaching $\sim 200 \mu \mathrm{g} / \mathrm{m}^{3}$. In 


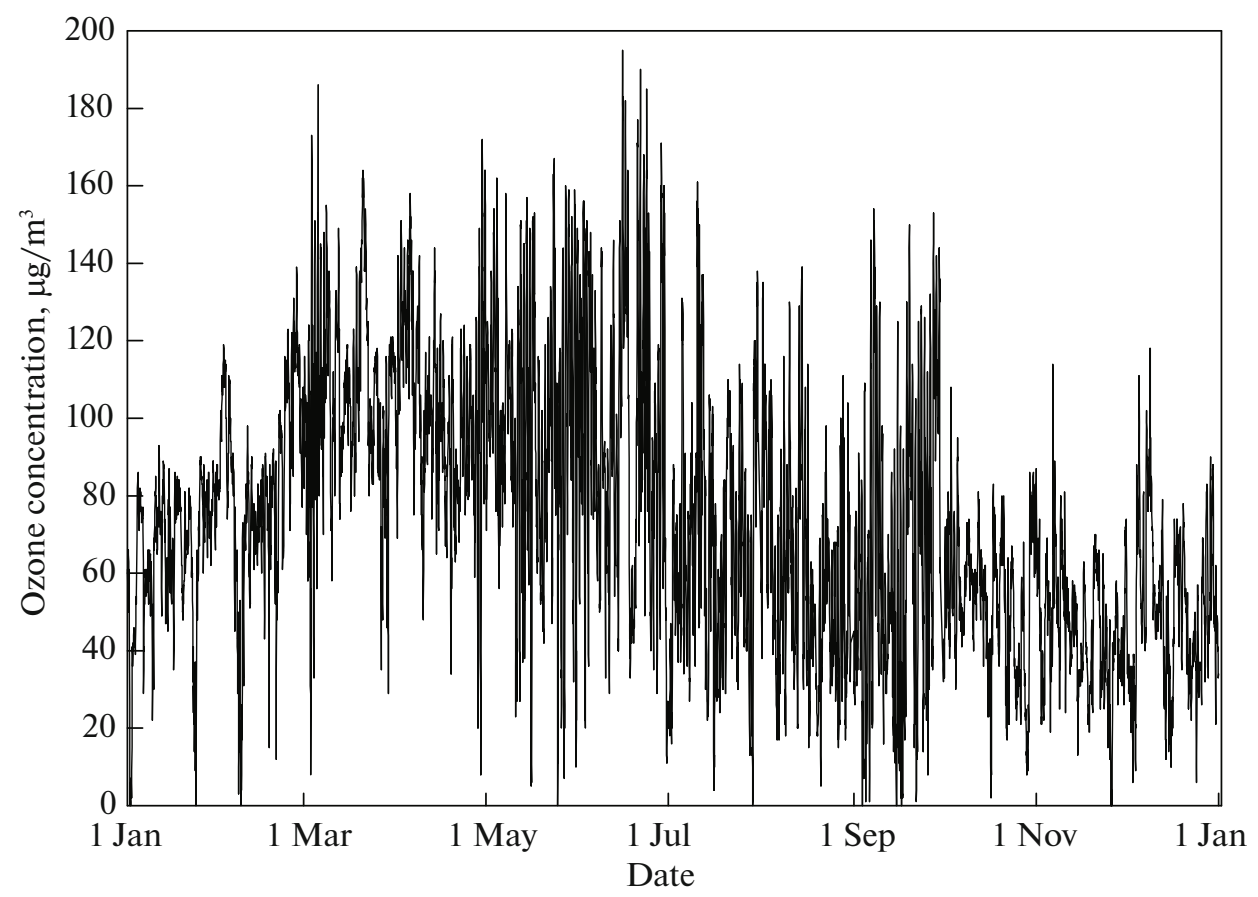

Fig. 1. Typical annual variation of surface ozone concentrations at the Vyatskie Polyany station, 2015.

autumn and in winter, when the solar illumination intensity decreases, the ozone concentration in the surface atmosphere decreases.

The long-term continuous monitoring of the ozone concentration in the surface atmosphere in a relatively pure (background) region allows observation of long-term trends caused by an increase in the total atmospheric pollution and climatic changes (temperature increase, an increase in the frequency of heat waves and an increase in their amplitude).

\section{MONITORING RESULTS}

Our close attention was directed to an analysis of the ozone content in the surface atmosphere at the beginning of 2020, when the COVID-19 pandemic began all over the world, and the activity of road and aviation transport, as well as some industrial enterprises, was limited in many countries were published [3-6]. In particular, it was fixed by satellite monitoring methods [7].

In this context, we performed a comparative analysis of the ozone concentration in the surface atmosphere in 2019 and 2020 at the Vyatskie Polyany station. Figure 2 shows the time variation of daily maximum 1-hour $\mathrm{O}_{3}$ concentrations in January-May 2019 and 2020. We note that the observed rapid fluctuations of the data shown in Fig. 2 are caused by day to day variations of meteo parameters (temperature, illumination, humidity, and wind direction).

We can see in Fig. 2 that the ozone concentrations observed in 2020 are lower than in 2019 over the entire observation period. A noticeable deviation begins as early at the end of January. In this case, the air temperature at the beginning of 2020 was on average slightly higher than in 2019, which would cause higher $\mathrm{O}_{3}$ concentrations. In February, the disagreement of measured values gradually increases; at the beginning of March 2020, an abrupt decrease in the ozone content in the atmosphere is observed. This time point coincides with the introduction of "high alert measures" in Russia since March 5, 2020, associated with the COVID-19 pandemic, i.e., the first limitations for the activity of road and aviation transport.

To improve the accuracy of the analysis of the observed phenomenon, we used time series processing based on the calculation of the hourly daily variations averaged over a month. In addition to a decrease in the random spread of observed data in amplitude due to averaging over a long time interval (month), this approach make it possible to retain information about diurnal dynamics and to separate contributions of 


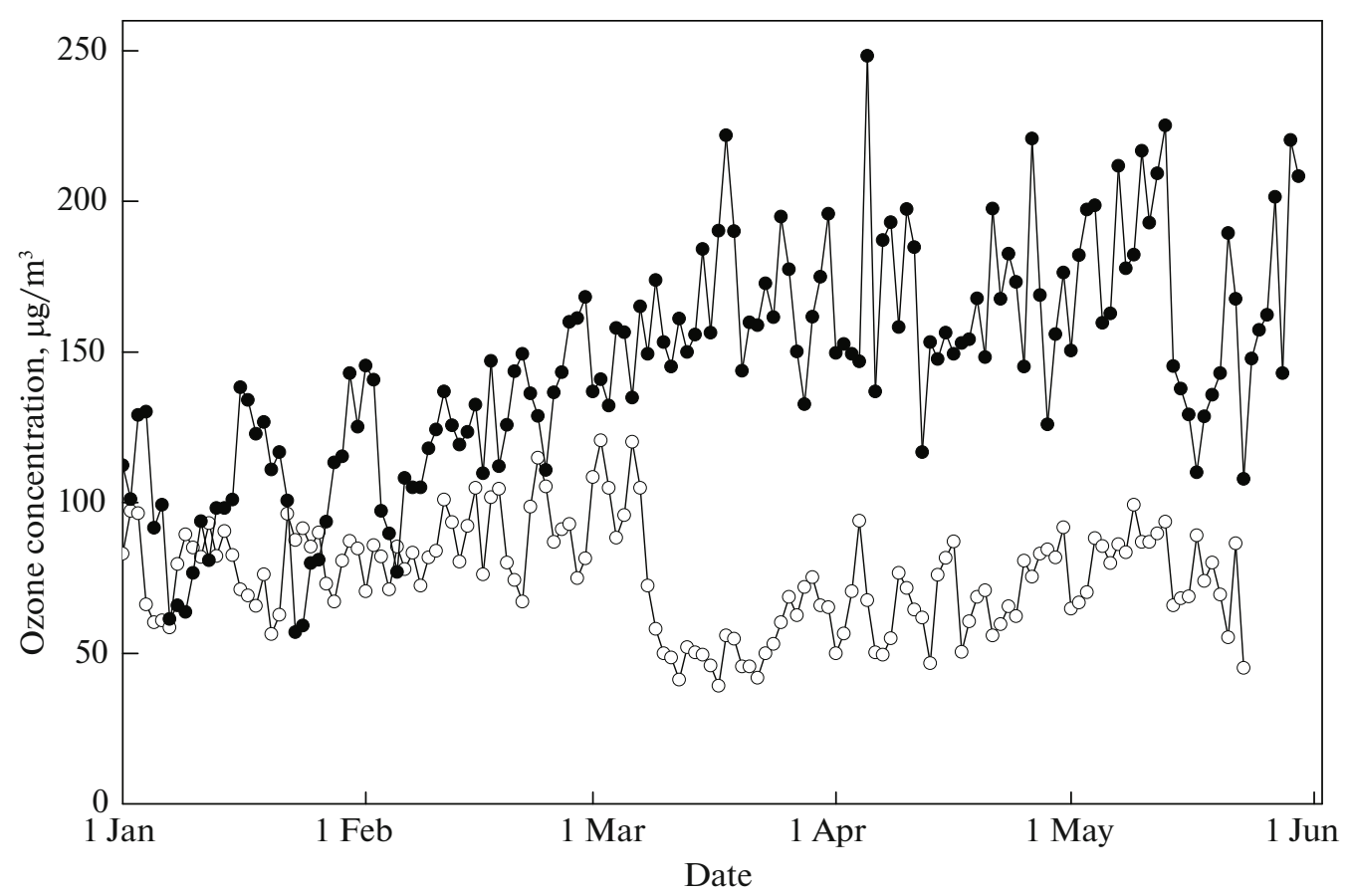

Fig. 2. Time variation of daily maximum 1-hour surface ozone concentrations from January 1 to June 1, 2019 (close circuits) and 2020 (open circuits), Vyatskie Polyany, Kirov oblast.

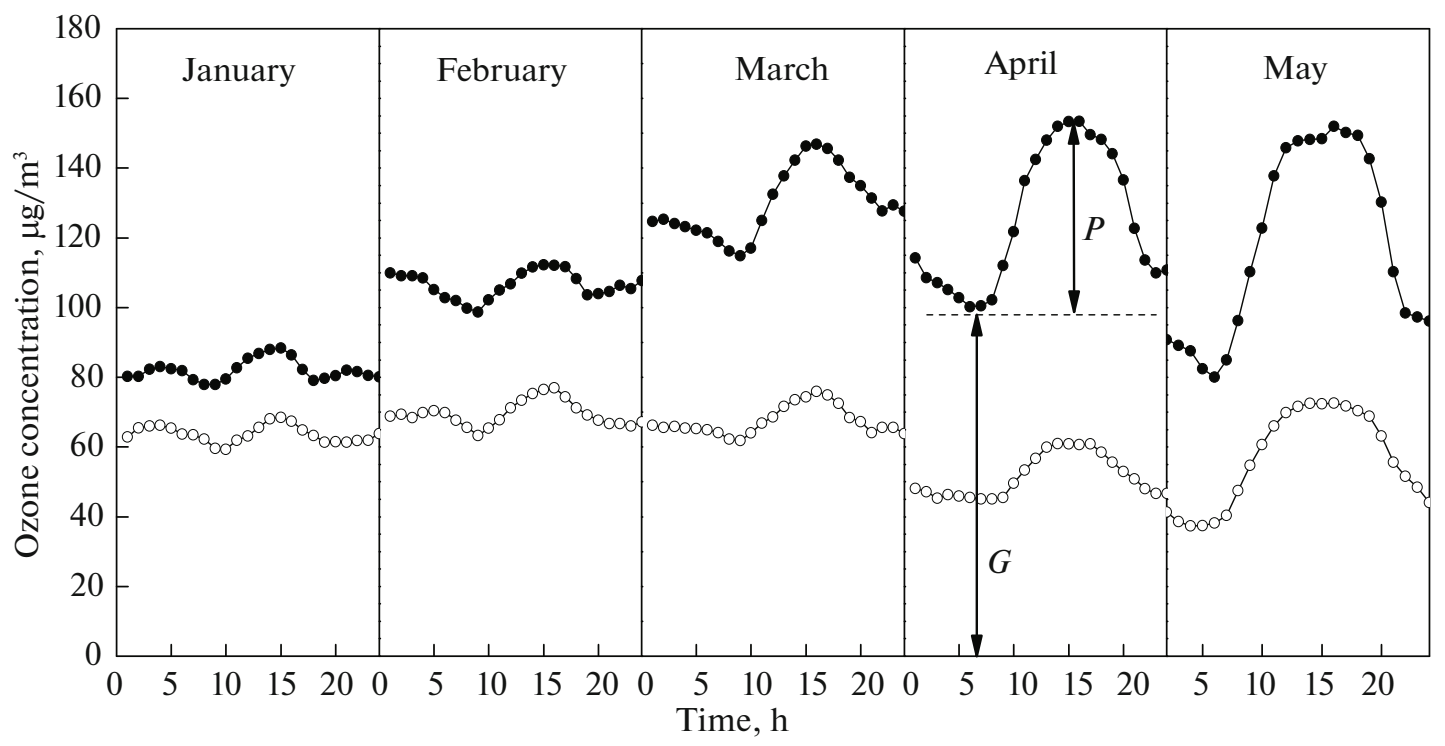

Fig. 3. Monthly averaged hourly daily variations of the $\mathrm{O}_{3}$ concentrations for January-May 2019 (closed circled) and 2020 (open circles).

photochemical mechanisms of ozone formation and production, prevailing in the daytime, and ozone transport and sink processes in the night. The data processing results are shown in Fig. 3, are shown.

As seen in Fig. 3, the daily variations of 2019 obey the usual trend, i.e., a characteristic spring increase in the ozone concentration from month to month is observed. The maximum average values increase from $\sim 90 \mu \mathrm{g} / \mathrm{m}^{3}$ in January to $\sim 155 \mu \mathrm{g} / \mathrm{m}^{3}$ in May. In 2020, anomalous dynamics is observed. For January 2020 , the values are $\sim 20 \%$ less than in 2019. In February, a still larger (by $\sim 35 \%$ ) difference between maxima of 2019 and 2020 is observed, which reaches $~ 50 \%$ in March. 


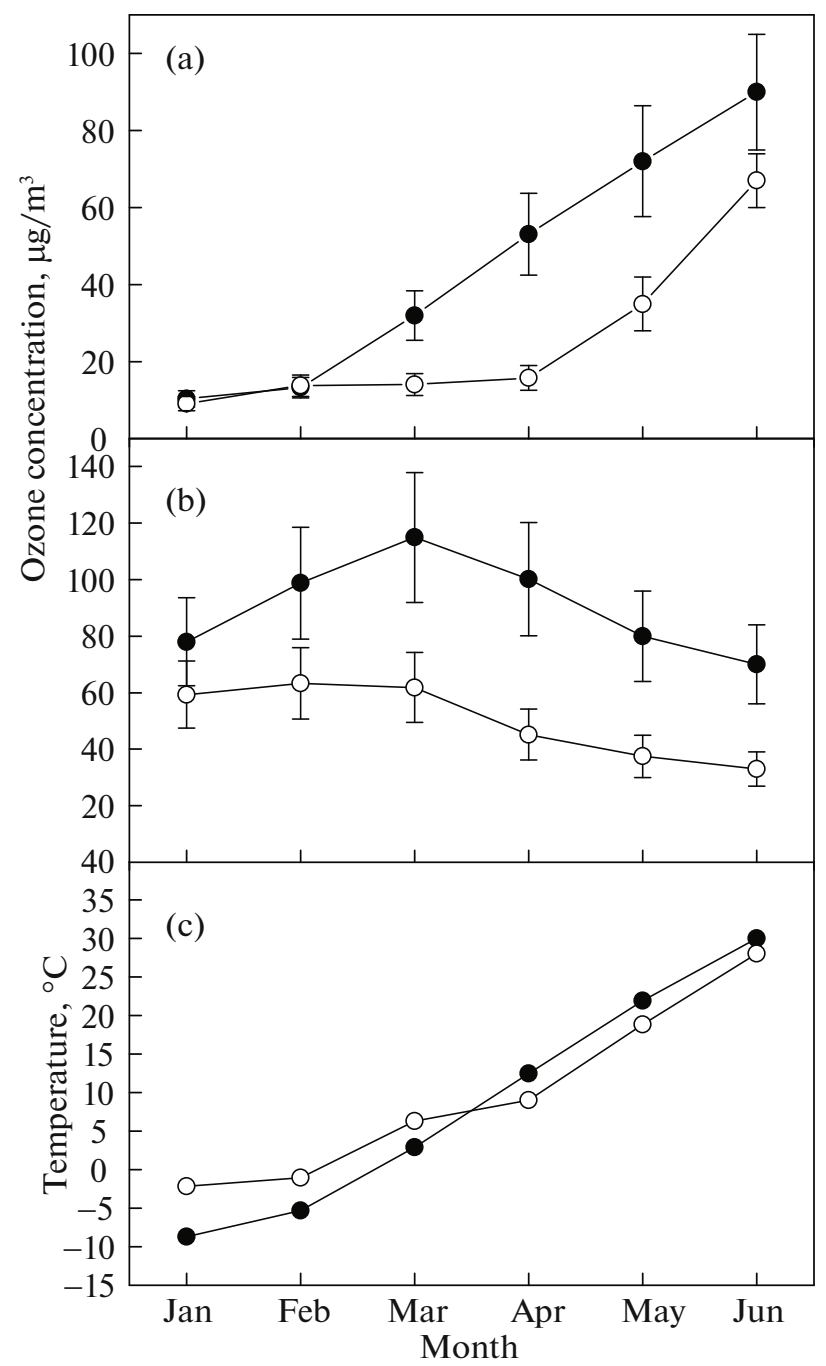

Fig. 4. Variations of the amplitude of acquired daily maxima $P(a)$, morning minima $G(b)$ and temperature (c) in January-June 2019 (closed circled) and 2020 (open circles).

Despite the increase in the seasonal temperature, solar radiation, and daylight duration, a still larger deviation from the values of 2019 is observed. In April 2020, a maximum decrease in ozone concentrations is observed, i.e., the amplitude of the day maximum which is usually caused by air pollution by ozone precursors, becomes almost three times lower than in April 2019, and is $\sim 60 \mu \mathrm{g} / \mathrm{m}^{3}$. In May 2020, the observed ozone concentrations also remain significantly (more than two times) lower than those fixed in 2019.

Figure 4 compares of the diurnally acquired maxima (Fig. 4a) and morning minima (Fig. 4b) for monthly daily variations shown in Fig. 3. These values are denoted in the April section in Fig. 3 by arrows $P$ and $G$, respectively. Furthermore, Fig. $4 \mathrm{c}$ shows the monthly averaged maximum temperature. The morning minimum $G$ is defined by the regional background and depends on the total mass of ozone photochemically formed in the region on the eve, the intensity of scavenging and dry deposition of ozone and its transfer from neighboring regions. At constant deposition and transfer, the morning minimum will gradually decrease with decreasing air pollution leading to a decrease in the formed ozone mass. The amplitude of the daily acquired maximum is controlled by the local diurnal concentration of pollutants involved in the photochemical formation of ozone. As seen from the dynamics of daily variations, the locally acquired ozone rather rapidly decays at nightfall.

Figure 4 shows that the dynamics of the ozone content generated in the daytime differs significantly in 2019 and 2020. In 2019, this value increases correlating with the temperature increase. In 2020, such a clear dependence is not observed. From January to April 2020, this value varies rather insignificantly. 
A considerable increase in the acquired maximum in 2019 and a significantly slower acquisition in 2020 at close temperature conditions indicate the integrally purer local air in 2020 in comparison with 2019.

The dynamics of morning minimum concentrations in 2019 and 2020, shown in Fig. 4b, also differs significantly. In 2019, the seasonal variation of minimum ozone concentrations, typical of winter and spring, is observed: initially, this parameter increases reaching a maximum in March, then it abruptly decreases until autumn similarly to that shown in Fig. 1 for 2015. The minimum ozone concentrations observed in spring months 2020 are two times lower than in 2019, and their monotonic decrease in time is observed. If it is considered that the ozone deposition in 2019 and 2020 differs only slightly, significantly lower morning ozone concentrations in 2020 can indicate a considerable decrease in the regional background of atmospheric air pollution in comparison with 2019 . The daily smaller ozone production in the daytime leads to a gradual decrease in the background regional concentration.

The most probable cause of a decrease in both background and peak local and regional ozone concentrations in ambient air in spring 2020 can be a decrease in the atmospheric pollution, caused by a decrease in the economic activity in China, Europe, and Russia in connection with the COVID-19 pandemic. The development of the anomalous dynamics of the tropospheric ozone in central Russia coincide with the introduction of road transport restrictions and a global decrease in the economic activity in the world, resulted in a considerable decrease in combustion product emissions into the atmosphere all over the world.

\section{CONCLUSIONS}

In central Russia, April 2020, anomalously low ozone concentrations in the surface atmosphere were recorded. The increase in the ozone concentration, usual for spring, caused by a seasonal increase in the temperature and light was followed by a monotonic decrease. The monthly averaged maximum diurnal

values observed in April 2020 were almost three times lower than those fixed at the same time in 2019.

In spring of 2020, both a decrease in regional background ozone concentrations in the surface atmosphere, and a decrease in the intensity of its photochemical formation were observed. The most probable cause of the observed phenomenon is a decrease in combustion product emissions into the atmosphere in China, Europe, and Russia due to the COVID-19 pandemic.

\section{REFERENCES}

1. S. N. Kotelnikov and E. V. Stepanov, "Positive Trend of Surface Ozone in the North of the Privolzhskii Federal Region of the Russian Federation,” Bull. Lebedev Phys. Inst. 45, 24 (2018).

2. V. P. Chelibanov, S. N. Kotelnikov, N. V. Smirnov, and E. A. Yasenko, "Application Prospects of the PAE-8816 Hardware-Software System in the Construction of the Global Monitoring System of Atmospheric Air," Biosfera 7, 119 (2015).

3. R. Zhang, Y. Zhang, H. Lin, Xu Feng, T.-M. Fu, and Y. Wang, "NOx Emission Reduction and Recovery during COVID-19 in East China," Atmosphere 11, 433 (2020). https://doi.org/10.3390/atmos11040433

4. P. Kumari and D. Toshniwal, "Impact of Lockdown Measures during COVID-19 on Air Quality - A case study of India International Journal of Environmental Health Research,” 2020.

5. M. Bauwens, S. Compernolle, T. Stavrakou, J.-F. Müller, J. van Gent, H. Eskes, P. F. Levelt, R. van der A, J. P. Veef kind, J. Vlietinck, H. Yu, and C. Zehner, "Impact of Coronavirus Outbreak on $\mathrm{NO}_{2}$ Pollution Assessed Using TROPOMI and OMI Observations," Geophys. Res. Lett. 47, 087978 (2020). https://doi.org/10.1029/2020GL087978

6. https://www.weforum.org/agenda/2020/04/coronavirus-covid19-air-pollution-enviroment-nature-lockdown

7. https://neo.sci.gsfc.nasa.gov/view.php? datasetId=AURA_NO2_M

Translated by A. Kazantsev 